\title{
Reciprocal constructions in Mian $^{1}$
}

3 Abstract: Despite the ongoing interest in reciprocal situations, which form a central

4 part of our social, intellectual and moral lives, and the linguistic encoding of such

5 situations in different languages, studies of reciprocals in Papuan languages remain

6 under-represented in the reciprocal literature. The Trans New Guinea languages

7 Mian, Amele and Hua have a reciprocal construction in which the reciprocal

8 subevents are expressed by individual transitive verbs plus an existential verb

9 expressing that the reciprocal action is done together. Mian goes one step further

10 and fuses this construction into a single verb with a reciprocal suffix -sese. The

11 present paper is an in-depth analysis of the morphology, syntax and semantics of

12 reciprocal constructions in Mian, including a comparison with Amele, and an

13 analysis of the diachronic development of the Mian reciprocal, whose origin

14 presumably lies in a biclausal description in which the reciprocal subevents are

15 spelled out separately and sequentially.

17 Keywords: reciprocals; transitivity; Trans New Guinea; Mian; Amele.

\footnotetext{
${ }^{1}$ Acknowledgements: I am grateful to two anonymous reviewers for Studies in Language. I thank Nick Evans, Grev Corbett, Volker Gast and Patricia Cabredo Hofherr for reading earlier drafts. Their comments greatly improved the paper. All shortcomings and errors are my own. I am also grateful to Kasening Milimap and Liden Milimap, who contributed a wealth of data on Mian reciprocals. The work reported here was supported under the European Science Foundation's EuroBABEL programme (project 'Alor-Pantar languages: origin and theoretical impact'), funded by the Arts and Humanities Research Council (UK) under grant AH/H500251/1. The fieldwork I conducted for this paper was funded by the Australian Research Council Discovery project 'Reciprocals across languages'. I thank these funding bodies for their support. Correspondence address: Sebastian Fedden, Surrey Morphology Group, School of English and Languages, University of Surrey, Guildford GU2 7XH, United Kingdom. E-mail: s.fedden@surrey.ac.uk.
} 


\section{Introduction}

22 In recent years there has been a strong theoretical and typological interest in the

23 study of reciprocal constructions and the situations for whose description they are

24 employed in the languages of the world (Dalrymple, Kanazawa, Mchombo \& Peters

25 1994, 1998; Frajzyngier \& Curl 2000; Behrens 2007; Nedjalkov 2007a; König \&

26 Gast 2008; Evans 2010; Evans, Gaby, Levinson \& Majid 2011). This literature

27 investigates a wide range of types of such constructions, yet contains only little on

28 reciprocals in Papuan languages, though some interesting facts have been noted

29 about the Trans New Guinea (TNG) languages Amele (Roberts 1987) and Hua

30 (Haiman 1980), where multi-verb constructions with a special type of switch-

31 reference marking are used to express reciprocal situations. These points are taken up

32 by Evans $(2008,2010)$ and will figure prominently in this article.

33 This type of reciprocal construction is restricted to Papuan Highlands languages.

34 The Papuan language Mian (TNG, Ok family; Fedden 2011) has two related

35 reciprocal constructions which are similar to those found in Amele or Hua. ${ }^{2}$ The aim

36 of this paper is to give a thorough synchronic and diachronic analysis of these two

37 constructions, which are interesting to typologists in general, to anyone working on

38 or interested in reciprocals, and to historical linguists as an unusual construction for

39 which a source can be continuingly reconstructed.

\footnotetext{
2 There are chapters dedicated to reciprocals in the Papuan languages Savosavo (Wegener 2011), Rotokas (Robinson 2011), and Yélî Dnye (Levinson 2011) in the volume by Evans, Gaby, Levinson and Majid (2011). None of these are TNG languages and they do not have the complex constructions found in Mian.
} 
40 The first construction type is illustrated in examples (1) to (3). Examples (4) to (7)

41 below illustrate the second type. Both types are dedicated reciprocals in the sense

42 that they can only have reciprocal semantics. As more detailed explanation of the

43 component parts of these constructions will be provided in sections 2 and 3 I will just

44 highlight the most important features here.

(1) (i) $\quad$ i-nâ'-sese-bl- $\emptyset$-io=be

(3PL) PL.AN.O-hit.PFV-RECP-exist-IPFV-2/3PL.AN.SBJ=DECL

'They (more than two) are hitting each other.'

50 The reciprocal morpheme is -sese. The free pronoun is optional (hence in 51 brackets) but if present it has to be in the plural. The reciprocants have to be encoded 52 as both subject and object. The reciprocal verb remains transitive. The whole set of 53 reciprocants is cross-referenced on the verb as subject (suffixal -io) and object 54 (prefixal $i$-) and the cross-referencing affixes are both in the plural. Example (1) can 55 only be used if there are more than two participants involved in a reciprocal action. If 56 there are exactly two participants of the same sex-and only in this case-(2) or (3)

57 have to be used. They cannot be used otherwise. 
(3) (i) $\quad w a-n a \hat{a}^{\prime}-$ sese-bl- $\emptyset$-io=be

67 In (2) and (3) everything is as in (1) with the exception that the object prefix has 68 to be in the singular and reflect the gender of the participants, i.e., $a$ - 'third person 69 singular masculine' or $w a$ - 'third person singular feminine'. Throughout this paper I 70 will call the construction exemplified in (1) to (3) the sese-construction because it 71 contains the reciprocal suffix -sese.

72 There is an alternative construction for (1), (2), and (3), illustrated in (4) with a 73 plural object prefix, (5) with a 'third person singular masculine' prefix and (6) with a 74 'third person singular feminine' prefix:

75

76

(4) (i) $\quad i-n \hat{a}^{\prime}-s-e$ $i-n \hat{a}{ }^{\prime}-s-e$ (3PL) PL.AN.O-hit.PFV-DS.SEQ-3SG.M.SBJ PL.AN.O-hit.PFV-DS.SEQ-3SG.M.SBJ

78

79

$b l-\emptyset-i o=b e$

80 exist-IPFV-2/3PL.AN.SBJ=DECL 'They (more than two) are hitting each other.'

82

(5) (i) $\quad a-n \hat{a}^{\prime}-s-e$ 


\begin{tabular}{|c|c|c|c|}
\hline 86 & & $a-n \hat{a}-s$ & \\
\hline 87 & & 3SG.M. & O-hit.PFV-DS.SEQ-3SG.M.SBJ \\
\hline 88 & & & \\
\hline 89 & & $b l-\varnothing-i c$ & $=b e$ \\
\hline 90 & & exist-II & FV-2/3PL.AN.SBJ=DECL \\
\hline 91 & & 'They & (two males) are hitting each other.' \\
\hline 92 & & & \\
\hline 93 & (6) & (i) & $w a-n \hat{a}^{\prime}-s-e$ \\
\hline 94 & & (3PL) & 3SG.F.O-hit.PFV-DS.SEQ-3SG.M.SBJ \\
\hline 95 & & & \\
\hline 96 & & wa-nâ & $-s-e$ \\
\hline 97 & & 3SG.F. & -hit.PFV-DS.SEQ-3SG.M.SBJ \\
\hline 98 & & & \\
\hline 99 & & $b l-\varnothing-i$ & $=b e$ \\
\hline 100 & & exist-I & FV-2/3PL.AN.SBJ=DECL \\
\hline
\end{tabular}

102

103 This particular type of reciprocal construction has been called the 'zigzag' type by 104 Evans $(2008,2010),{ }^{3}$ and this is the term I will use as well. This construction is 105 illustrated in examples (4) to (7). The reciprocal subevents of hitting appear in a 106 serial verb construction. The subevents are expressed sequentially by two verbs,

\footnotetext{
${ }^{3}$ Evans (2008) calls these 'zigzag summative constructions', Evans (2010) 'unified zigzag constructions' but the idea and the analysis provided are the same.
} 
107 whose lexical stem is always identical, in this case $-n \hat{a}$ ' 'hit (PFV)'. These are the

108 zigzag verbs expressing the individual subevents within a larger reciprocal event.

109 If there are more than two participants, the object prefix must be in the plural, as

110 in (4). If there are two participants of the same sex object inflection reflects the

111 gender of the two participants, as in (5) and (6). There is an existential verb at the

112 end of the serialization carrying the subject inflection, which is always plural

113 expressing the full set of reciprocants. There is no morpheme -sese in this

114 constructional variant. Instead the zigzag verbs each carry a switch-reference

115 suffix $-s$ indicating 'different subject, sequential' in an atypical circular fashion

116 referencing each other, followed by a subject suffix. The latter is frozen to the third

117 person singular masculine. This can be seen in (7) below, where the subject of the

118 first zigzag verb is the female participant (hitting the male participant), yet the

119 subject suffix is $-e$, and not the expected $-o$ 'third person singular feminine'.

120 If the set of reciprocants consists of one male and one female participant the

121 zigzag construction has to be used. One verb carries a masculine object prefix, the

122 other a feminine object prefix. Example (7) has no equivalent sese-construction:

$124 \quad(7) \quad(\bar{l}) \quad a-n \hat{a}^{\prime}-s-e$

125 (3PL) 3SG.M.O-hit.PFV-DS.SEQ-3SG.M.SBJ

126

127 wa-nâ'-s-e

128 3SG.F.O-hit.PFV-DS.SEQ-3SG.M.SBJ 
130

131

132

133

134 In both reciprocal constructions the reciprocants have to be animate. Events

135 involving inanimate participants cannot be encoded with either the sese- or the

136 zigzag-construction. The corpus does not contain any such examples and constructed

137 examples involving inanimate reciprocants were consistently rejected by speakers.

138 After discussing both types of Mian reciprocal (-sese and zigzag) in detail

139 including their semantics I propose a historical scenario in section 6 which traces the

140 zigzag reciprocal construction back to its origin as a biclausal description involving a

141 clause chaining construction in which medial verbs are marked for different subject

142 relative to the subject of the succeeding clause. I propose that the constructions

143 exemplified in (1) to (3) are essentially fused versions of the zigzag constructions

144 illustrated in (4) to (6), whereby the sequence $V$-s-e $V$-s-e of the zigzag reciprocal

145 was fused into $V$-sese.

146 The zigzag reciprocal construction can also be found in the TNG languages

147 Amele (Roberts 1987) and Hua (Haiman 1980). Below I discuss the zigzag

148 reciprocal in Amele in more detail. However, neither Amele nor Hua have gone as

149 far as Mian, i.e., to the point of fusing the zigzag construction into a single predicate

150 with a unique and segmentable reciprocal morpheme (-sese in Mian).

151 The data presented in this paper are from the eastern Mian dialect and are mainly 152 descriptions of reciprocal situations, elicited with the help of 64 video clips devised 
153 by the Reciprocals project at the Max Planck Institute for Psycholinguistics,

154 Nijmegen (Evans, Levinson, Enfield, Gaby \& Majid 2004; Evans, Gaby, Levinson,

155 \& Majid 2011). The clips are available at http://fieldmanuals.mpi.nl/login/referer/.

156 These data are supplemented with elicited examples from my own corpus and with

157 examples from the Mian New Testament (Smith \& Weston 1986). All Mian data

158 presented in this paper were collected by the author. The source is given in square

159 brackets for examples from the spontaneous corpus and examples from the responses

160 to the video clips. Other elicited examples are unmarked.

161 Mian belongs to the Ok family of languages, which is named after the widespread

162 word $o k$ 'river, water' (Healey 1964; Voorhoeve 2005). The Ok family belongs to the

163 larger TNG family (Wurm 1982; Ross 2005; Pawley 2005). Mian is spoken in

164 Telefomin District of Sandaun Province in Papua New Guinea. The eastern dialect

165 has approximately 1,400 speakers and is the base for a comprehensive grammatical

166 description of the language (Fedden 2011). Most speakers under 75 also speak Tok

167 Pisin, the variety of Neo-Melanesian Pidgin spoken in Papua New Guinea. Most

168 young speakers have some knowledge of English. Older male speakers above 50

169 years of age also speak or at least understand the closely related neighboring

170 language Telefol.

171 Mian is a word tone language, i.e., the domain in which five lexically specified

172 tonal melodies contrast is the entire phonological word and not the syllable

173 (Donohue 1997). In the examples, the five tonal melodies are written as follows: mēn

174 'child' (H), mén 'string bag' (LH), klâ 'properly' (LHL), fè 'carrion' (HL). Low tone 175 is unmarked: am 'house' (L). 
176 For roughly two thirds of the verb stems that have been recorded in the corpus

177 (comprising roughly 300 verb stems) there is a perfective-imperfective distinction in

178 the stem. Whenever a verb stem is cited its aspect value is given in brackets if a

179 given stem is unequivocally perfective of imperfective, such as baa 'say (PFV)' and $o$

180 'say (IPFV)'. For trans-aspectual verbs, which can be used in the perfective and the

181 imperfective, a single form is given, e.g., $f u$ 'cook'.

182 Mian is head-marking (Nichols 1996). The neutral word order is $\mathrm{S}(\mathrm{O}) \mathrm{V}$ in all

183 clause types but constituent order is relatively free with the restriction that the verb

184 always has to be clause-final and is only followed by an illocutionary particle. Word

185 order within the NP is fixed. The language is strongly zero-anaphoric, i.e., all

186 argument NPs are typically elided, if referent identity is retrievable from the context

187 or world knowledge. The syntax of the language is characterized by very frequent

188 use of serial verb constructions and clause chaining with anticipatory switch

189 reference marking.

190 Before delving into the analysis of Mian reciprocals I give a brief sketch of two

191 important characteristics of Mian morphosyntax which are important for

192 understanding reciprocal constructions. These are argument cross-referencing and

193 switch reference (S/R) in clause chains, which have already been touched upon in the

194 introductory remarks. These grammatical areas are important because the

195 reciprocants are indexed by means of affixes and the sese-reciprocal is presumably

196 the result of a historical development whose origin was a clause chaining

197 construction involving S/R marking. 
202 Mian verb morphology is complex and mildly polysynthetic. For the discussion of 203 reciprocals, we need to look at the subject, object, and recipient affixes for animates,

204 all of which are marked on the verb by means of an affix. The language does not 205 have morphological case or adpositional marking for core grammatical relations.

206 Instead, all subjects are obligatorily indexed on all finite verb forms by a pronominal 207 suffix, regardless of whether they are subjects of an intransitive or a transitive clause, 208 whereas objects are marked by a pronominal or a classificatory prefix for some verbs 209 and not at all for other verbs, as will be explained below. Whether a verb indexes its 210 object is lexically determined. An example of an intransitive verb is (8):

(8) $\bar{e} \quad g e n-b-e=b e$ 3SG.M be_sick.IPFV-IPFV-3SG.M.SBJ=DECL 'He is sick.'

216 Most transitive verbs in Mian do not index their object. An example of such a 217 verb is dowôn' 'eat (PFV)', as in (9): 
223 There are two classes of transitive verbs that do index their objects. The first class

224 indexes the object with a pronominal prefix. This class comprises seven verb stems

225 only, namely -têm' 'see (PFV)', -temê' 'see (IPFV)', -lò 'hit, kill (PFV)', -nâa' 'hit, kill

226 (PFV)', -e 'hit, kill (IPFV)', -ntamâ' 'bite (PFV)', and -f $\hat{u}$ ' 'grab (PFV)', all of which-

227 with the notable exception of 'see' - are high on the transitivity scale (Hopper \&

228 Thompson 1980). An example is (10):

(10) $n a k a=e \quad$ unáng $=o \quad$ wa-têm'- $\emptyset-e=b e$

'The man saw the woman.'

There is a second type of object prefix which is obligatory for about 50 verbs,

235 almost exclusively verbs of object handling, such as 'give', 'put', 'throw', 'get', and

236 'turn' (Fedden 2011: 194-195). ${ }^{4}$ These classificatory prefixes index the object, signal

237 number and classify the object according to certain salient characteristics of its

238 referent, viz. sex, shape, and function. Example (11) shows the transitive verb -ò 'get

239 (PFV)' with the classificatory prefix tob-, which is used for long objects in the

240 singular, for example a single tobacco leaf.

$t o b-\grave{o}-n-i=a$

\footnotetext{
${ }^{4}$ Classificatory prefixes operates on an absolutive basis (Keenan 1984), i.e., the prefix classifies the object of transitive verbs and the subject of the intransitive verb 'fall', which is never reciprocal and therefore ignored here.
} 
'Now I get the tobacco leaf, and then I ...' [Rolling smokes]

246 Unlike such languages as Waris (Brown 1981; Seiler 1983), the classificatory

247 morphemes in Mian cannot be traced back to source verbs. The classificatory

248 prefixes form a second system of nominal classification apart from the gender

249 system. $^{5}$ They are not agreement affixes but verbal classifiers (Aikhenvald 2000:

250 152). The forms of the classificatory prefixes are given in Table 1.

252 [Insert Table 1 about here]

254 Recipient objects are indexed with a suffix in the verb - $\hat{u} b$ '- 'give (PFV)' in the 255 perfective. $^{6}$ The imperfective forms attach to the suppletive form - $k a$ - 'give (IPFV)'. 256 On triple agreement in the ditransitive verb - $\hat{u} b$ '- 'give (PFV)' (which indexes the 257 subject, the recipient and the theme), see Fedden (2010: 461-462, 477-482). Both $258-\hat{u} b^{\prime}-$ and $-k a$ - obligatorily index the theme object (the gift) with a classificatory 259 prefix. An example of - $\hat{u} b$ '- 'give (PFV)' is (12):

$$
\text { (12) } n \bar{e} \quad n a k a=e \quad \text { éil }=o
$$

1SG man=SG.M pig=SG.F

\footnotetext{
${ }^{5}$ The class containing male referents (and some inanimates) is called the M-class and the class containing female referents (and many inanimates) is called the F-class. This is a reminder that these classes are similar to 'masculine' and 'feminine', respectively, but they cannot be called that because the terms are already in use for two of the Mian genders.

${ }^{6}$ This verb has the allomorphs $-\hat{u} t$ '- before $/ \mathrm{n} /$ and $-\hat{b} b$ '- after a vowel (and - $t$ ' - between a vowel and $/ \mathrm{n} /$ ) where only /b/ (or / $/$ ) is realized segmentally but the LHL tone remains. The apostrophe indicates that the verb is off-stem accented, which means that the tonal melody attaches to the tone-bearing unit immediately to the right of the verb root.
} 
$o m-\hat{u} b^{\prime}-a-\emptyset-i-b i o=b e$

3SG.F_CL.O-give.PFV-3SG.M.R-REAL-1SG.SBJ-GPST=DECL

'I gave the sow to the man.'

268 In the perfective, lexical verbs are compounded with - $\hat{u} b$ '- 'give (PFV)' to

269 introduce a recipient object into the argument structure of the verb. The recipient

270 object is indexed by means of a suffix immediately following -ûb'- 'give (PFV)'.

271 Note that $-\hat{u} b$ '- 'give (PFV)' does not have a classificatory prefix in this construction.

272 An example is (13):

273

$274 \quad$ (13) $k a s a k=e$

275

kasak_ritual=SG.N1

276

277

ale- ${ }^{\wedge} b^{\prime}-e-\emptyset-i b-b i o=t a$

278

show-give.PFV-PL.AN.R-REAL-2/3PL.AN.SBJ-GPST=MED

279

'they had shown us the Kasak (ritual), and then ...' [Kasak ritual]

280

281 While subject and object affixes are independent of aspect the form of the suffix

282 indexing the recipient depends on aspect. In the imperfective the recipient suffixes

283 have slightly different forms and are appended to the verb stem directly. An example 284 is (14):

285

286 (14) unín=o ifu-ye-b-o=be 
food $=\mathrm{N} 2 \quad$ serve.IPFV-PL.AN.R-IPFV-3SG.F.SBJ=DECL

'She is serving food for us / you (PL) / them.'

290 The forms of all argument cross-referencing affixes in the third person are given

291 in Table $2^{7}$

292

293 [Insert Table 2 about here]

295 There is some allomorphy in the plural object prefixes. The verb $-e$ 'hit, kill 296 (IPFV)' takes $y$-, and -nâ' 'hit, kill (PFV)' takes $y a$ - or $i$-. The remaining five verbs 297 take $y a-$.

$300 \quad 1.2$ Clause chaining and switch reference marking

302 Clause chaining constructions are a typical feature of Mian discourse and widespread

303 in TNG languages (Foley 2000: 357). Clause chains consist of one or more medial

304 clauses and one final clause. The former have medial verbs with anticipatory S/R

305 morphology relative to the following clause, indicating co-reference or disjoint

306 reference of the subject (Stirling 1993). Final verbs, on the other hand, are inflected

307 for various tense categories, polarity and illocutionary force, which have scope over

308 the whole clause chain (Foley \& Van Valin 1986; Reesink 1983). As clause chains in

\footnotetext{
${ }^{7}$ The allomorphy conditions for the subject suffix are complicated (depending on both the phonological and the morphological context) and irrelevant for the purpose of this paper (see Fedden 2011: 262-265).
} 
309 Mian can be very long it is often necessary for practical reasons to confine an

310 example to a part of the clause chain in order to make a certain point. In this case the

311 example might not contain a final clause. An example illustrating a part of a clause

312 chain is given in (15):

313

314

(15) a. tóm=e belâ-s-e=ta

b. min ye fiou fiou $g a-b-e=t o$

stone=SG.N1 open.PFV-DS.SEQ-3SG.N1.SBJ=MED hitting his adversaries who were trying to prevent him from leaving through the opening)' [Danenok and his brother]

323 In (15) subject reference is disjoint. The subject in clause (a) is the stone, the

324 subject in clause (b) the male protagonist. This is indicated by the suffix $-s$ on the 325 verb belâ 'open (PFV)'. For the Mian reciprocal construction only the 'different 326 subject' suffixes $-s$ and $-b$ are relevant. Mian S/R suffixes also carry information

327 about event sequentiality or simultaneity. The suffix $-s$ has event sequentiality as part 328 of its meaning, the suffix $-b$ has simultaneity as part of its meaning. These two 329 suffixes are contrasted in a very similar frame in (16) and (17):

(16) $\bar{e} \quad$ bín $=o \quad$ we $-s-e=a$ 
naka $\quad$ unín $=o \quad f u-n-e-b i o=b e$

man other=SG.M food=N2 cook-REAL-3SG.M.SBJ-GPST=DECL

$$
\text { (17) } \bar{e} \quad \text { bin }=o \quad \text { we }-b-e=a
$$$$
\text { 3SG.M floor=N2 sweep-DS.SIM-3SG.M.SBJ=MED }
$$

$$
\text { naka } \quad \text { unín }=o \quad f u-b-e=b e
$$

345 The S/R suffixes $-s$ and $-b$, both of which signal disjoint subject reference and 346 which are associated with perfective and imperfective aspect, respectively, play an

347 important role in the zigzag reciprocal construction and are the key to the diachronic 348 scenario which I propose in section 6. For a detailed description and analysis of the

349 Mian S/R system, see Fedden (2011: 421-470) and Fedden (2012). 
354 The topic of this section is the reciprocal construction with the reciprocal

355 suffix -sese. The only function of this construction is to encode reciprocal situations.

356 The construction does not participate in any reflexive, collective, or distributive

357 polysemies. An example of a transitive verb inflected with -sese is (18):

3PL PL.AN.O-hit.PFV-RECP-exist-IPFV-2/3PL.AN.SBJ=DECL

'They are hitting each other.' (i.e., are engaged in reciprocal hitting)

364 subject suffix has to be plural, expressing the whole set of reciprocants. I analyze the

365 existential verb as a suffix because the whole verb complex in (18) forms a single

366 phonological word with respect to tone assignment and because the initial /b/ in the

367 existential verb is not prenasalized, which it would be in isolation. The construction

368 illustrated in (18) has a number of interesting properties which I point out in the

369 following.

370 First, the suffix -sese cannot be used with imperfective stems. It can be appended

371 only to perfective stems or trans-aspectual stems, which do not formally distinguish

372 between perfective and imperfective aspect. The suffix occurs directly after the stem

373 or if the verb is compounded with $-\hat{u} b$ '- 'give (PFV)' after the recipient suffix; see

374 examples (22) to (24) below. The existential verb at the end of the sese-construction

375 also has the aspectual function of expressing imperfectivity. It does not only serve as

376 the host for the subject inflection. As -sese can only be used in the perfective an

\footnotetext{
${ }^{8}$ The allomorphy works as follows: $b l$ is chosen before /i/, $b i$ is chosen elsewhere.
} 
377 additional verb introducing imperfectivity is necessary, if one wants to describe an

378 on-going situation which consists of bounded reciprocals subevents.

379 Second, and more importantly, reciprocants have to be (i) subjects and (ii) one of 380 either object or recipient, depending on the argument structure of the verb. It is 381 typologically unusual for a reciprocal construction employing a verb-marking 382 strategy that both reciprocant argument positions have to be filled and that the 383 reciprocal verb remains transitive (Nedjalkov 2007b: 12, 40). ${ }^{9}$ The whole set of 384 reciprocants is cross-referenced on the existential verb. The subject affix is always in 385 the plural. The object affix is in the plural, if there are more than two reciprocants 386 (cf. example (1) above). It is in the singular, if there are exactly two reciprocants of 387 the same sex (cf. examples (2) and (3) above). (For two reciprocants of different sex 388 the zigzag construction has to be used; see example (7) above).

389 In example (18) above and example (19) immediately below the reciprocants are 390 the subject and the object:

(19) $\bar{l} \quad y a-t e ̂ m '-s e s e-b l-\emptyset$-io=be 3PL PL.AN.O-see.PFV-RECP-exist-IPFV-2/3PL.AN.SBJ=DECL 'They are looking at each other (i.e., exchanging glances with each other).'

396 The object index can come from the set of classificatory prefixes as well. An 397 example is provided in (20):

\footnotetext{
${ }^{9}$ On transitive reciprocals in Oceanic languages, see Moyse-Faurie (2008: 154). On transitive reciprocals in Seri, an isolate from northern Mexico, see Marlett (2005: 61).
} 


$$
\text { (20) } \bar{l} \quad \operatorname{mak}=i \quad \operatorname{dim}
$$

3PL other=PL.AN on

406 Reciprocants can also be the subject and the recipient, which in the perfective is 407 always indexed with a suffix on the verb - $\hat{u} b$ '- 'give (PFV)' (on the allomorphy, see 408 footnote 6). This recipient suffix can refer to a proper recipient of some physical 409 transfer of an object (21), the recipient of a verbal message (22), a benefactive 410 possessor (23) or a malefactive possessor (24):

$$
\text { (21) } n a k a=i=a \quad \text { unáng }=a=i
$$


other=PL.AN

423

$o-\emptyset \frown$-yen-sese-bl- Ø-io=be

PL.RESID.O-give.PFV-PL.AN.R-RECP-exist-IPFV-2/3PL.AN.SBJ=DECL

'While men and women are sitting they take all sorts of things and give

$m a k=i$

$m e m \hat{e}=i$

$k l a ̂$

3PL other=PL.AN children(PL)=PL.AN very

(24) $\bar{l}$ am $a s=o$ 
'They are burning (lit. setting fires to) each other's houses.'

446

447 The reciprocal suffix is always -sese regardless of the person value of the 448 reciprocants. This can be seen from example (25), where the reciprocants are in the 449 first person:

450

$$
\text { (25) nībo ya-têm'-sese-bi- Ø-obo=be }
$$

455 In each of these examples, the existential verb $b i \sim b l$ is imperfective and means 456 'they are (there)', thus denoting a reciprocal event which is on-going at the moment 457 of speaking or takes place habitually. The existential verb takes regular inflection, for 458 example -so to express the hesternal past:

(26) $\bar{\imath} \quad i$-nâ'-sese-bi-n-ib-so=be 'Yesterday they were hitting each other.'

465 to signal imperfective aspect. This aspectual function is the same as in non-reciprocal 466 predicates, where the existential verb expresses a continuous action, as in (27): 
468

469

470

471

472 When the set of reciprocants is larger than two all cross-referencing affixes

473 indexing the reciprocants have to be in the plural. In a reciprocal situation with only

474 two participants object affixes must appear in the singular though the subject suffix

475 remains plural, as in (28), contrasted with the ungrammatical utterance in (29):

unán

$a s u$

$u l a ́ a b=i$

$[\ldots]$

479

480

481

woman two age_mate=PL.AN

[...]

482

483

mele-^b’-o-sese-bl- $\emptyset$-io=be

484

485

486

wéng $=o \quad o$-biaan-ib $=a$

language $=\mathrm{N} 2$ say.IPFV-exist.IPFV.SS.SIM-2/3PL.AN.SBJ=MED

487

488

(29) *unáng asú uláab=i

489

woman two age_mate $=$ PL.AN

490 
504 possible:

505

506

507

508

509

dowôn'-sese-bl- $\emptyset$-io=be 3PL eat.PFV-RECP-exist-IPFV-2/3PL.AN.SBJ=DECL

'They eat each other.'

\section{2 [repeated from (20)]:}

\footnotetext{
${ }^{10}$ Note that on its own the verb in (29) is fine and means 'they (more than two) are touching each other', but it cannot be used for just two participants who are engaged in a reciprocal action.
} 
$514 \quad$ (31) $\bar{\imath} b \quad$ sinwalo klâ

2PL brothers properly

go- ${ }^{\prime} b^{\prime}-e-\operatorname{sese}-n-i n=e$ !

(32) $\bar{\imath} \quad \operatorname{mak}=i \quad \operatorname{dim}$

3PL other=PL.AN on

do-tamaa-sese-s-ib=a

528 Summarizing, there are four templates for the sese-construction. Template 1 is 529 used if a verb indexes its object with a pronominal or a classificatory prefix. 530 Template 2 is used for the verb $-\hat{u} b$ '- 'give (PFV)', which indexes the (recipient) 531 object with a suffix. It is also employed for the zero root - $\emptyset^{\wedge}$ - 'give (PFV)', which 532 shows up in some of the examples in this article. (For more information on the zero 533 root, see Fedden 2010: 469-470). Template 3 is employed if a verb combines with $534 \hat{u} b^{\prime}$ - 'give (PFV)', which indexes the (recipient) object with a suffix. The templates 535 under (a) where the non-subject reciprocant argument is plural are used for more than 
536 two reciprocants. The templates under (b) where the non-subject argument is singular 537 are used for exactly two reciprocants (of the same sex). Template 4 is used for 538 transitive verbs that do not index their object. In this case it is not necessary to 539 distinguish between subtypes (a) and (b) because the verbs following this template 540 do not have object affixes which would be able to encode a number difference 541 between a singular and a plural object. There can be more than two reciprocants or 542 exactly two of the same or different sex.

544 Template 1 a. PL.O- $\mathrm{V}_{\text {stem }}$-sese-exist-IPFV-PL.AN.SBJ=DECL

b. SG.O-V stem -sese-exist-IPFV-PL.AN.SBJ=DECL

Template 2 a. CP-give-PL.R-sese-exist-IPFV-PL.AN.SBJ=DECL

b. CP-give-SG.R-sese-exist-IPFV-PL.AN.SBJ=DECL

a. (CP-) $\mathrm{V}_{\text {stem }}$-give-PL.R-sese-exist-IPFV-PL.AN.SBJ=DECL

b. $(\mathrm{CP}-) \mathrm{V}_{\text {stem }}$-give-SG.R-sese-exist-IPFV-PL.AN.SBJ=DECL

555 The brackets in template 3 indicate the presence of a classificatory prefix if the 556 verb which is compounded with $-\hat{u} b$ '- 'give (PFV)' takes a classificatory prefix, 557 e.g., -tanà 'set(fire) (PFV)' in (24) above, or the absence of the prefix in verbs which 558 do not take them, e.g., baa 'say (PFV)' in (22) above. The classificatory prefixes in 559 templates 2 and 3 index the theme and do not enter into reciprocal relations. 
560 Reciprocal relations can only be expressed between agent and patient or agent and

561 recipient (Fedden 2010: 473-474).

562

563

5643 The zigzag reciprocal construction

565

566 In this section I look in detail at the second reciprocal, the zigzag construction. Like

567 the sese-construction it is a dedicated reciprocal. Contrary to the sese-construction,

568 which is a single word, the zigzag construction consists of three words. The

569 examples (33) and (34) below illustrate this variant for the verb -têm' 'see (PFV)',

570 which obligatorily indexes its object with a prefix, and the verb mele- 'touch (PFV)',

571 which must form a compound with -ûub'- 'give (PFV)' followed by a recipient suffix.

572 Example (35) illustrates the zigzag construction with a verb that does not index its

573 object.

574

$575 \quad$ (33) $\bar{l} \quad a-t e ̂ m^{\prime}-s-e$

576 3PL 3SG.M.O-See.PFV-DS.SEQ-3SG.M.SBJ

577

578

wa-têm's-e

579

3SG.F.O-see.PFV-DS.SEQ-3SG.M.SBJ

580

581

$b l-\emptyset-i o=b e$

582

exist-IPFV-2/3PL.AN.SBJ=DECL 
'They (F+M) are throwing glances each at the other.'

584

585

(34) $\bar{l}$ mele- ^b'-o-s-e

586

3PL touch.PFV-give.PFV-3SG.F.R-DS.SEQ-3SG.M.SBJ

587

588

mele- $b^{\prime}-a-s-e$

touch.PFV-give.PFV-3SG.M.R-DS.SEQ-3SG.M.SBJ

590

591

$b l-\emptyset-i o=b e$

592

exist-IPFV-2/3PL.AN.SBJ =DECL

593

'They (M+F) are touching each other.'

594

595

596
(35) $\bar{\imath}$ dowôn's-e
dowôn'-s-e
3PL eat.PFV-DS.SEQ-3SG.M.SBJ
eat.PFV-DS.SEQ-3SG.M.SBJ

597

598

$b l-\emptyset-i o=b e$

599

exist-IPFV-2/3PL.AN.SBJ =DECL

600

'They eat each other.'

601

602 The suffix $-s$ is a S/R marker indicating 'different subject' and 'sequentiality of 603 events' (introduced in section 1.2 above) and $-e$ is a conventionalized form of the 604 subject cross-referencing suffix frozen to the third person singular masculine 605 whatever the person, number or gender of the reciprocants actually is. 
606 As in the sese-construction there is a final existential verb in the (animate) plural 607 summarizing the reciprocal action as a whole and indexing the whole set of 608 reciprocants. The existential verb has the aspectual function of expressing 609 imperfectivity. As the subevents which are expressed in the zigzag verbs are 610 perfective an additional verb introducing imperfectivity is necessary, if one wants to 611 describe an on-going situation which consists of such bounded reciprocal subevents.

612 The zigzag construction is restricted to the third person. The following example

613 (36) was rejected as ungrammatical:

614

615

(36) *nībo na-têm'-s-e

617

618

ka-têm's-e

619

2SG.O-See.PFV-DS.SEQ-3SG.M.SBJ

620

621

$b i-\emptyset-o b o=b e$

622

exist-IPFV-1PL.SBJ=DECL

623

Intended: 'We (INCL, i.e., you and me) are throwing glances at each other.'

624

625 The zigzag construction is formed according to the following four templates.

626 Template 5 is used if a verb indexes its object with a pronominal or classificatory

627 prefix. Template 6 is for $-\hat{u} b$ '- 'give (PFV)' (and for - $\varnothing$ - ' 'give (PFV)') and Template 7 
628 for verbs compounded with $-\hat{u} b$ '- 'give (PFV)'. Transitive verbs which do not index

629 their object (see subsection 1.1 on argument marking) use Template 8.

630

631

632
Template 5 a. PL.O- $\mathrm{V}_{\text {stem }}-s-e$
PL.O- $\mathrm{V}_{\text {stem }}-s-e$
exist-IPFV-PL.AN.SBJ=DECL
b. SG.O- $\mathrm{V}_{\text {stem }}-s-e$
SG.O- $\mathrm{V}_{\text {stem }}-s-e$
exist-IPFV-PL.AN.SBJ=DECL

633

634

635
Template 6 a. CP-give-PL.R-s-e
CP-give-PL.R-s-e
exist-IPFV-PL.AN.SBJ=DECL
b. CP-give-SG.R-s-e
CP-give-SG.R-s-e
exist-IPFV-PL.AN.SBJ=DECL

a. (CP-) $\mathrm{V}_{\text {stem }}$-give-PL.R-s-e

$(\mathrm{CP}-) \mathrm{V}_{\text {stem}}$-give-PL.R-S-e

exist-IPFV-PL.AN.SBJ=DECL

b. (CP-) $\mathrm{V}_{\text {stem }}$-give-SG.R-s-e

$(\mathrm{CP}-) \mathrm{V}_{\text {stem-give-SG.R-s-e }}$

exist-IPFV-PL.AN.SBJ=DECL

642 The Mian zigzag reciprocal construction has the following noteworthy features:

643 First, the verbs describing the subevents - of throwing glances in (33) and of

644 touching in (34) - have subject suffixes in the expected slot but these subject suffixes

645 are in the third person singular masculine $(-e)$ regardless of the actual person, number

646 or gender of the reciprocants. The transitive verbs describing the subevents have two

647 argument slots each. They are regular transitive verbs with the exception that the

648 subject suffix is always $-e$.

649 Second, the DS suffix $-s$, which is normally only anticipatory, indicating that the

650 verb of the next clause has a different subject, shows an unusual non-linear or

651 circular behavior. For the second verb DS marking is not calculated with respect to

652 the third verb (the existential verb) but rather with respect to the first. If it was 
653 calculated with respect to the existential verb we would expect SS marking to be

654 possible in the second verb because SS marking is the default if the set of referents of

655 the subject in one clause is properly included in the set of referents in the following

656 clause (Fedden 2011: 460). Yet, only DS marking is possible in reciprocals.

657 These features are highly reminiscent of what can be found in the TNG language

658 Amele (of the Gum family, spoken in Madang Province). Roberts (1987: 306) points

659 out that "[b]oth coordinate verbs are marked for third person singular subject and for

660 different subject (DS) following. Therefore they cross reference each other even

661 though they are in linear sequence". Also see Haiman (1980: 433) on the circular

662 behavior of S/R marking in Hua reciprocals. An example from Amele is (37):

663

664

665

666

(37) Amele

667

$$
\begin{array}{llll}
\text { age } & q e t-u-d o-c o-b & q e t-u-d o-c o-b & e i g-a \\
\text { 3PL } & \text { cut-PRED-3SG-DS-3SG } & \text { cut-PRED-3SG-DS-3SG } & \text { 3PL.SBJ-TODPST }
\end{array}
$$

'They cut each other.' (Roberts 1987: 132)

668

669 The way reciprocals are expressed in Amele depends on whether the reciprocating

670 roles are between agent and patient, as in (37), or between agent and recipient, in

671 which case a slightly different construction has to be used. An example is (38):

672

673 (38) Amele

674

age jacas qet-i do-co-b do-co-b eig- $a$

675 3PL tobacco cut-PRED 3SG-DS-3SG 3SG-DS-3SG 3PL.SBJ-HODPST 
678 In (38), the lexical verb appears only once and what constitutes the zigzag verbs is

679 a reduplication of some material, which according to Robert's gloss does not seem to

680 contain any lexical material. Evans (2010: 82fn52) proposes the following alternative 681 analysis for the zigzag verbs docob docob in (38), based on the fact that 'give' is a 682 zero-root verb in Amele (according to Roberts 1987; also see Z'graggen 1975, 1980).

683 On the exceptional grammatical behavior of 'give'-verbs cross-linguistically, see 684 Comrie (2003).

(39) Amele

687 $d o-\emptyset-c o-b$ 3SG-give-DS-3SG 'He gives (to) him.'

691 If this analysis was correct then (38) would be literally 'they $\mathrm{k}_{\mathrm{k}+1}$ tobacco cut 692 he $_{\mathrm{k}}$.gives.him he $_{1}$.gives.him $\mathrm{k}_{\mathrm{k}}$ they $\mathrm{k}_{\mathrm{k}+\mathrm{l}}$.are', where $\mathrm{k} \neq 1$. The indices are meant to 693 express the disjoint-subject meaning. Although a plausible analysis, it runs into 694 problems because the prefix do- is not part of any of the Amele object paradigms, all 695 of which are exclusively suffixal to boot (Roberts 1987: 279; Roberts 1998: 3).

696 Roberts (1998: 20, 25-27) interprets the lexical stem of 'give' as suppletive with 697 respect to the recipient. The form $u t-e c$ 'give to him/her' is analyzed as follows: 
(40) Amele

700

$u t-e c$

701

give.3SG.IO-INF

702

'give to him/her'

703

An alternative analysis of 'give' in Amele has been proposed by Reesink (pers.

705 comm., and discussed in Fedden 2010: 465), where 'give' is analyzed as a minimal

706 root $i$ - $\left(u\right.$ - in $3^{\text {rd }}$ person) followed by an indirect object suffix, e.g., $u-t-e c$ [give-

707 3SG.IO-INF] 'give to him/her'. ${ }^{11}$ Following this analysis reciprocal giving in Amele

708 looks like (41):

709

$710 \quad$ (41) Amele

711

712

age ceb

$u-t e-c e-b$

$u-t e-c e-b$

eig-a

3PL betelnut give-3SG-DS-3SG give-3SG-DS-3SG

3PL.SBJ-TODPST

713

'They give each other betelnut.' (Roberts 1987: 132)

714

715 We find, however, a generic verb that is suppletive with respect to person with the

716 form $d o$ - in the third person singular. Consider example (42) ${ }^{12}$ :

\footnotetext{
${ }^{11}$ In the free verb 'give', $i$ - $\sim u$ - does not occur in 2/3DU and 2/3PL, while it does show up when 'give' is attached to another verb. Compare (i) with (ii) and compare (iii) with (iv). Note that Reesink proposes incidental elision of /i/ in the free verb 'give' preceding /a/.

(i) $a l-e c(* i-a l-e c)$ 'to give to you/them (dual)'

(ii) siw-i-al-ec [share-give-2/3DU-INF] 'share for you/them (dual)'

(iii) $a d-e c(* i-a d-e c)$ 'to give to you/them (plural)'

(iv) siw-i-ad-ec [share-give-2/3PL-INF] 'share for you/them (plural)'

${ }^{12}$ In (42) the gloss 'do' for $d o$ is mine. Roberts only glosses it as 3SG. This verb is also used as a generic verb with Tok Pisin loans, for example:

(1) wa pumpim do-g-a

water(TP) pump(TP) do.3SG-2SG-IMP

'Pump the water!' (Roberts 1987: 312)
} 
$718 \quad$ (42) Amele

oso wen do-i-a

720 someone hunger do.3SG-3SG.SBJ-TODPST

721 'Someone is hungry.' (Roberts 1987: 146)

723 Another reason why the analysis of the Amele zigzag reciprocal in (38) above as

724 involving a morpheme 'give' is dubious is the fact that 'give' in Amele is $u$ - in the

725 third person. So even if one wanted to say that the morpheme $-i$ in (38), which

726 Roberts glosses as PRED, is really 'give' one faces the problem that it should be $u$ - in

727 the third person.

728 To sum up the discussion on zigzag reciprocals in Amele, I assume that the verb

729 involved is not 'give', but rather a suppletive generic verb, whose form in the third

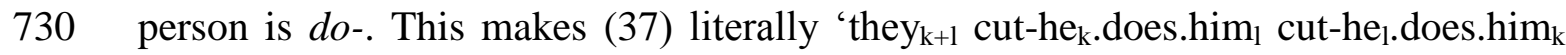

731 the $_{\mathrm{k}+1}$.are', where $\mathrm{k} \neq 1$, and (38) would be literally 'they $\mathrm{k}_{\mathrm{k}+1}$ tobacco cut he $\mathrm{k}_{\mathrm{k}}$.does.him

732 he $_{1} \cdot$ does.him $_{\mathrm{k}}$ they $\mathrm{k}_{\mathrm{k}+1}$.are', where $\mathrm{k} \neq 1$.

733 The Mian and Amele zigzag reciprocals are very similar in structure. In such

734 zigzag constructions a complex form of verb chaining is zigzagging between

735 subevents, i.e., successive transitive verbs, each marked with a different subject

736 marker, and agreeing with one actor in person and number, albeit in fossilized form,

737 followed by an intransitive summary auxiliary agreeing with the whole set of 738 reciprocants. 
739 In the zigzag construction we have a situation where the entities which denote the

740 subevents remain distinct phonological words, i.e., there are three distinct verbs,

741 namely the two zigzag verbs and the auxiliary. This raises the question of how many

742 verbs and how many clauses should these be analyzed as having.

743 This question is typologically relevant because languages differ in how much

744 complexity, in terms of event structure, they allow to be accommodated in one

745 clause. Reciprocals are an especially interesting case because they are complex event

746 types which derive from the overlay of two propositions sharing the same predicate

747 but with converse argument configurations (see for example Evans 2010: 6), e.g., in

748 the English sentence $X$ and $Y$ hit each other, $\mathrm{X}$ and $\mathrm{Y}$ are simultaneously agent and

749 patient. English does not mind organizing a reciprocal event in a single clause; it

750 even lexicalizes them, e.g., they meet/fight/marry (König \& Kokutani 2006). One

751 argument position of a transitive verb is filled by a conjoined NP, a plural pronoun or

752 a plural NP, referring to the full set of participants. The other argument position is

753 filled by the bipartite reciprocal anaphor each other, while in other languages, e.g., in

754 the Papuan language Golin (Chimbu) reciprocal situations have to be expressed with

755 a biclausal description of the type $N P_{k} V-s N P_{l}, N P_{l} V-s N P_{k}$, where $\mathrm{k} \neq 1$. Again

756 consider the Mian zigzag construction, repeated from (33), where one man and one

757 woman participate in the reciprocal event:

758

$759 \quad$ (43) $\bar{l} \quad$ a-têm'-s-e

760 3PL 3SG.M.O-See.PFV-DS.SEQ-3SG.M.SBJ 

'They (F+M) are glancing at each other.'

766 Semantically, we are clearly dealing with three subevents expressed by three

767 verbs which make up the larger reciprocal event. These subevents (abbreviated 'se' 768 below) can be described as follows:

774 Mian, similarly to Amele, makes overt all the semantic components of a 775 reciprocal event. Each of the three subevents are expressed by one verb. The first two 776 subevents are mapped onto the transitive zigzag verbs with "the difference in agent

$777[\ldots]$ motivating the anomalous 'backward-looking switch-reference' in the second 778 conjoined verb" (Evans 2010: 33). That the whole complex event is a joint activity is 779 expressed by the third verb, which bears the plural subject suffix. ${ }^{13}$ These languages 780 make the semantic structure of the reciprocal event obvious.

781 However, it is much less clear whether we are also dealing with three distinct 782 clauses. There are two arguments for assuming that there is only one clause.

\footnotetext{
${ }^{13}$ In this sense the Mian construction is bordering on collectivity or sociativity (cf. Nedjalkov 2007b: 33)
} 
783 First, in Mian (as in Amele) subject agreement in zigzag-constructions is 784 conventionalized and frozen, i.e., into third person singular $-b$ in Amele and third 785 person singular masculine $-e$ in Mian. This seems to support the assumption that 786 zigzag verbs do not constitute heads of their own clauses but are rather elements of a 787 larger serial verb construction. See Evans (2008: 82-83) for a parallel argument for 788 Amele.

789 Second, no material can intervene between the zigzag verbs. For example, they 790 cannot be followed by the clitic $=a$, which marks verbs as medial in clause chaining 791 constructions. Consider example (44):

792

793

(44) $\bar{l} \quad a$-têm' $-s-e\left({ }^{*}=a\right)$

795 'They are touching each other.'

800 This is in contrast to example (45), which provides a biclausal description of two 801 sequential events taking place between the participants:

802

$803 \quad$ (45) $\bar{o} \quad a$-têm' $-s-o=a$

804 3SG.F 3SG.M.O-see.PFV-DS.SEQ-3SG.F.SBJ =MED 


$$
\bar{e} \quad w a-t e ̂ m^{\prime}-s-e=a
$$

3SG.M 3SG.F.O-See.PFV-DS.SEQ-3SG.M.SBJ =MED

810 To sum up, synchronically the Mian zigzag reciprocal unifies three events into a

811 single clause. The two arguments for this analysis are, first, that the subject suffixes

812 are frozen to the third person singular masculine regardless of the actual person,

813 number and gender of the reciprocants and that, second, no material may come

814 between the zigzag verbs in monoclausal reciprocal constructions.

815 In the following section I take a closer look at the semantics of the sese- and the 816 zigzag construction.

\section{The semantics of the sese- and the zigzag constructions}

821 The sese-construction can be employed for a variety of reciprocal situations. It can

822 be used for situations of strong reciprocity, where the reciprocal relation obtains

823 between all members of the set of participants, which is typologically typical (Evans,

824 Gaby, Levinson \& Majid 2011), but it is also possible in cases in which the 825 saturation of possible interrelations is relaxed, for example in melee, chaining or 826 adjacent configurations. All of these are discussed in more detail below. Each type of 827 reciprocal situation is illustrated with an example of the sese-construction, but the 828 zigzag construction would also be possible in each case. The semantic restrictions of 
829 either construction have to do with the number and gender of the reciprocants and

830 whether the reciprocal subevents may occur simultaneously or can only occur

831 sequentially. These issues are taken up at the end of this section.

832 In situations of strong reciprocity all possible interrelations are saturated as for

833 example in the sentence House of Commons etiquette requires legislators to address

834 only the speaker of the House and refer to each other indirectly (from Dalrymple,

835 Kanazawa, Kim, Mchombo \& Peters 1998: 168). A schematized version is given in

836 Figure 1.

837

838 [Insert Figure 1 about here]

839

840 Example (46) is a description of a situation in which there are a number of people,

841 all of whom shake everyone else's hand:

842

843

844

(46) mâa'-biaan-ib=a

stand_up.PFV-exist.IPFV.SS.SIM-2/3PL.AN.SBJ=MED

845

846

heitda-^b'-e-sese-bl- $\varnothing$-io $=b e$

847

shake_hands-give.PFV-PL.AN.R-RECP-exist-IPFV-2/3PL.AN.SBJ=DECL

848

'While standing, they shake each other's hands.' [MPI clip 38]

849

850 It is not necessary for all possible interrelations to be saturated for the Mian

851 reciprocal construction to be used, for example in melee configurations, where there 
852 is at least one participant who is only the endpoint and at least one participant who is

853 only the initiator of the action (Figure 2), for instance in The hungry rats eat each

854 other (Evans 2008: 40).

855

856 [Insert Figure 2 about here]

857

858 On a less violent note, the following description can be used for a situation in

859 which there are several giving events but the giving proceeded in a somewhat

860 unstructured fashion so that there is at least one participant who has not given

861 anything and at least one participant who has not received anything.

862

$863 \quad$ (47) $n a k a=i=a \quad$ unáng $=a=i$

$864 \quad \operatorname{man}=P L \cdot A N=$ and $\quad$ woman $=$ and $=P L . A N$

865

866

toula-biaan $-i b=a$

867

sit_down.PFV-exist.IPFV.SS.SIM-2/3PL.AN.SBJ=MED

868

869

870

inaminamino $\quad o l-\grave{o}-n-i b=a$

all_kinds_of_stuff PL.RESID.O-take.PFV-SEQ-2/3PL.AN.SBJ=MED

871

872

$m a k=i$

873

other=PL.AN

874 
880 Chaining situations are another possibility (Lichtenberk 1985: 24), i.e.,

$$
o-\emptyset^{\wedge}-y e n-s e s e-b l-\emptyset \text {-io=be }
$$

PL.RESID.O-give.PFV-PL.AN.R-RECP-exist-IPFV-2/3PL.AN.SBJ=DECL 'While men and women are sitting they take all sorts of things and give them to each other.' [MPI clip 21]

\section{1} configurations in which participant $\mathrm{A}$ is in a certain relation to participant $\mathrm{B}, \mathrm{B}$ to $\mathrm{C}$,

882 etc., so that the last participant is not initiator and the first participant is not endpoint 883 of the action, for example The pupils followed each other onto the stage, where the 884 first pupil is not following and the last one is not being followed (Figure 3).

$$
\text { kwīng hà'-^b’-e-sese-bl- Ø-io=be }
$$


'While standing they are hugging each other.' (Lit. are breaking each other's shoulders) [MPI clip 2]

900

901 Finally, adjacent configurations can be expressed as well, that is configurations in

902 which participants are adjacent to each other and A and B engage reciprocally, then

903 B and C, then C and D, etc., so that each participant is both initiator and endpoint in

904 any given reciprocal subevent (Figure 4).

905

906 [Insert Figure 4 about here]

907

908 An example of a reciprocal description of an adjacent situation is (49). This

909 description was given for a situation in which a number of people are hugging each

910 other pairwise, e.g., A and B embrace each other, then $\mathrm{C}$ and $\mathrm{D}$, then $\mathrm{E}$ and $\mathrm{F}$. If all

911 instances of embracing happened simultaneously the same description would be

912 possible.

913

914

(49) tub temwât $d l-\grave{a}$ sâ'-sese-bl- $\emptyset$-io=be $e^{14}$

915 chest across PL.AN.O-include.PFV-RECP-exist-IPFV-2/3PL.AN.SBJ=DECL

916 'They are embracing each other.' (Lit. they are including each other across the chest) [MPI clip 29]

\footnotetext{
${ }^{14}$ The verb form in this example is from the lexicalized tight serial verb construction -à sấ, which means 'involve, include'. The elements of this SVC do not appear to have an independent meaning synchronically but behave as two distinct phonological words with respect to tone assignment. The first verb has a HL tonal melody and the second one has a LHL melody.
} 
919 Note that different verbs were used in (48) and (49), which is probably due to the

920 different hugging style depicted in the clips. While (49) shows typical reciprocal

921 hugging in which both participants are hugging, in (48) only one participant is

922 hugging the other, who remains unresponsive.

923 Above I pointed out that both the sese- and the zigzag construction are subject to

924 certain semantic restrictions regarding the number and gender of the reciprocants and

925 whether they allow simultaneous reciprocal subevents as well as sequential ones. As

926 the restrictions cross-cut the sese-vs. zigzag distinction, I list all attested subtypes in

927 Table 3, together with a pertinent example in this paper.

928

929 [Insert Table 3 about here]

930

931 Let's first concentrate on the subtypes A to D, i.e., the sese-constructions.

932 Subtypes A and B are interesting because they are the ones with an object affix in the

933 singular. These are reserved for exactly two reciprocants of the same gender, as

934 encoded in the object affix, and require the reciprocal subevents to be symmetrical,

935 yet to proceed sequentially, i.e., each participant is both initiator and endpoint of the

936 reciprocal action ( $\mathrm{X}$ acts on $\mathrm{Y}$ and $\mathrm{Y}$ acts on $\mathrm{X}$ ), and the respective subevents occur

937 sequentially one after the other. An example of a description of such a situation is

938 given in (50):

939

940 (50) $n a k a=i \quad$ asú $k e-n-i b=a$

941 man=PL.AN two do-SEQ-2/3PL.AN.SBJ=MED 
mâa'-biaan-ib=a

stand_up.PFV-exist.IPFV.SS.SIM-2/3PL.AN.SBJ =MED

945

946

mak=e $\quad k w \overline{i n g}$

other=3SG.M shoulder

$h a \grave{\prime}-{ }^{\prime} b^{\prime}-a-s e s e-b l-\emptyset$-io=be

break.PFV-give.PFV-3SG.M.R-RECP-exist-2/3PL.AN.SBJ=DECL is then hugged by Y).' [MPI clip 58]

953

954 Reciprocal constructions in Mian show interesting cases of clashes between the 955 morphology and the semantics. While the agents in Mian reciprocals are always 956 collapsed in a plural subject suffix, the patients (or recipients) can be expressed 957 iconically to a certain degree, as illustrated by subtypes A and B, where the object 958 affix is in the singular, thus iconically expressing that the respective reciprocal 959 actions are directed towards individuals of the same sex. However, the configurations

960 for which $\mathrm{A}$ and $\mathrm{B}$ can be used are restricted to two participants. Note that this

961 amounts to a constructional encoding of a dual although the language does not have 962 dual agreements.

963 When there are more people involved in a reciprocal event, i.e., when two (or 964 more participants) are acting on one (or more participants) in a single reciprocal 
965 event or when there is more than one pair of reciprocants performing the same

966 reciprocal action within each pair, the object affix needs to be plural (subtype C).

967 The final subtype of the sese-construction is D, where there is no object affix on

968 the verb. In this case there are no semantic restrictions at all because there can be no

969 semantic clash of conflicting features due to the absence of object affixes.

970 Now we turn to the subtypes of the zigzag construction. Subtypes E and F are the 971 zigzag alternatives for A and B and the same restrictions obtain.

972 The subtype $\mathrm{G}$ has to be used when there are two reciprocants of opposite sex.

973 Consider example (51):

974

975

976

(51) $\bar{l} \quad$ mikim $=i$

a-têm's-se

3PL siblings_of_opposite_sex=PL.AN

3SG.M.O-See.PFV-DS.SEQ-3SG.M.SBJ

977

978

wa-têm's-e

$b l-\emptyset-i o=b e$

979

3SG.F.O-see.PFV-DS.SEQ-3SG.M.SBJ

exist-IPFV-2/3PL.AN.SBJ=DECL

980

'Brother and sister are glancing at each other.' [MPI clip 46]

981

982 In this case a single verb inflected with -sese cannot be used because this would

983 invariably create a semantic clash that the language does not permit. If example (51)

984 had a single verb inflected with -sese and the affix cross-referencing the non-subject

985 reciprocant was singular masculine there would be a clash with the fact that one of

986 the subevents is directed towards a woman. If it was singular feminine a similar clash

987 would arise in that one of the subevents is directed towards a man. Finally, plural 
988 non-subject affixes in Mian reciprocals are not allowed for just two reciprocants 989 since any single reciprocal subevent will only ever be directed towards a single 990 participant. However, when there is an additional participant of either sex one has to 991 move away from the compositional expression of patients (or recipients) and use 992 subtype $\mathrm{C}$ (or $\mathrm{H})$.

993 Parallel to subtype C, subtype $\mathrm{H}$ has plural object affixes. The conditions of use 994 are the same as for subtype C. As with the other subtypes with singular object affixes 995 (i.e., A, B, E, and F) simultaneous reciprocity is excluded for subtype $\mathrm{H}$ as well.

996 The final subtype of the zigzag-construction is F, where there are no object affixes 997 on the zigzag verbs. As with subtype D, there are no semantic restrictions.

998 Neither of the sese- nor the zigzag construction shows any restrictions with 999 irreducibly symmetric verbs, which are known to show constructional restrictions in 1000 many languages (Dimitriadis 2008). A predicate is irreducibly symmetric "if (a) it 1001 expresses a binary relationship, but (b) its two arguments have necessary identical 1002 participation in any event described by the predicate" (Dimitriadis 2008: 378). An 1003 example of an irreducibly symmetric verb is meet. It is due to the lexical semantics 1004 of this verb that an event of A meeting B is also always an event of B meeting A. 1005 Here, either the sese- or the zigzag construction can be used, so either (52) or (53) 1006 are possible, even in the description of exactly two people meeting each other.

(52) $\bar{\imath} \quad m \hat{\imath}{ }^{\prime}$-sese-bl- $\emptyset$-io=be 3PL meet.PFV-RECP-exist-IPFV-2/3PL.AN.SBJ=DECL

1010 'They (2 or more) met each other.' 

$m \hat{\imath}{ }^{\prime}-s-e$

1014

1015

$b l-\emptyset-i o=b e$

1016 exist-IPFV-2/3PL.AN.SBJ=DECL

1017 'They ( 2 or more) met each other.'

1018

1019 This is not restricted to verbs which do not index their object. An example of the 1020 zigzag construction with an irreducibly symmetric predicate heitda 'shake hands', 1021 which indexes the (recipient) object, is (54):

1022

$1023 \quad$ (54) $\bar{l} \quad$ heitda- ${ }^{\wedge} b^{\prime}-e-s-e$

1024 3PL shake_hands-give.PFV-PL.AN.R-DS.SEQ-3SG.M.SBJ

1025

1026

heitda- $b^{\prime}-e-s-e$ shake_hands-give.PFV-PL.AN.R-DS.SEQ-3SG.M.SBJ

1028

1029

$b l-\emptyset-i o=b e$

1030 exist-IPFV-2/3PL.AN.SBJ=DECL

1031 'They shake hands with each other.' 
1033 The following section dealing with reciprocals in the imperfective rounds off the 1034 synchronic analysis of reciprocal constructions in Mian.

1035

1036

\section{Reciprocals in the imperfective}

1038

1039 The sese-construction and its zigzag variant, both of which were discussed in the

1040 preceding sections, cannot be used in the imperfective. We find the zigzag

1041 construction in the imperfective which is used for situations where the subevents are

1042 presented as temporally extended and (at least partially) simultaneous. An example is 1043 (55):

1044

1045
$(55)$

unáng=i

asumâtna ke-n-ib=a

1046

woman=PL.AN three do-SEQ-2/3PL.AN.SBJ=MED

1047

1048

gokîm=i hen-ye-b-e

1049

head_louse=PL.AN look_for.IPFV-PL.AN.R-DS.SIM-3SG.M.SBJ

1050

1051

hen-ye-b-e

$b l-\emptyset$-io=be

1052

look_for.IPFV-PL.AN.R-DS.SIM-3SG.M.SBJ exist-IPFV-2/3PL.AN.SBJ=DECL

1053

'They are each looking for lice on the other.' [MPI clip 56]

1054 
1055 We immediately see many parallels to the zigzag construction in the perfective.

1056 However, let's first focus on the small but crucial differences. The main difference is

1057 that while the zigzag construction in the perfective uses the suffix $-s$ 'different

1058 subject sequential', the one in the imperfective uses the other different subject suffix

$1059-b$, whose meaning is 'different subject simultaneous'. The fact that Mian apparently

1060 recycled both DS markers-and only those-back into reciprocal constructions

1061 strengthens the diachronic scenario I propose below, namely that reciprocals

1062 developed from a clause chaining construction in which verbs were inflected for DS.

1063 The other difference between reciprocals in the perfective and the imperfective is

1064 that the former have the fused construction with a single reciprocal suffix -sese

1065 whereas there is no way of fusing the construction in (56) into a single verb with a 1066 suffix *-bebe. Such forms do not exist.

1067

1068

(56) *(i) hen-ye-bebe-bl- $\emptyset$-io=be

1069 3PL look_for.IPFV-PL.AN.R-RECP.IPFV-exist-IPFV-2/3PL.AN.SBJ=DECL

$1070 \quad$ Intended: 'They are looking for lice on each other.'

1071

1072 While example (56) is ungrammatical, many features of the zigzag construction in 1073 the imperfective in (55) above look familiar. The whole reciprocal event is expressed

1074 by three verbs. The first two specify the type of action that is performed reciprocally.

1075 These verbs index their object, i.e., are transitive and the subject suffix is frozen to 1076 the third person singular masculine $(-e)$. The verb hen 'be looking for' is an 1077 imperfective stem and can only be used in the imperfective. In contrast to the 
1078 perfective aspect where verbs have to be compounded with - $\hat{u} b$ '- 'give (PFV)' in

1079 order to introduce a recipient object, there is no such compound in the imperfective.

1080 The recipient suffix is directly appended to the verb stem, e.g., hen-ye-...

1081 [look_for.IPFV-PL.AN.R-...]. Furthermore, we find the same forms of the existential

1082 verb as the third verb in the construction. The arguments to set this up as a type of

1083 serial verb construction within a single clause are the same: (i) the subject suffix only

1084 appears in the frozen form and (ii) there can be no intervening material between any

1085 of the three verbs that make up the zigzag construction.

1086 To sum up, while we find many parallels between reciprocals in the perfective and

1087 the imperfective the latter do not show a fused reciprocal marker parallel to -sese in

1088 the perfective.

1089

1090

10916 Historical scenario for the origin of the sese-construction

1092

1093 In this section I propose a historical scenario according to which the zigzag 1094 reciprocal in Mian has grammaticalized from a reanalysis of a complex serial verb 1095 construction, ultimately deriving form a biclausal description of the reciprocal 1096 situation. The sese-construction in turn is a fused form of the zigzag construction. In 1097 the following I discuss each step of the proposed development.

1098

1099

$1100 \quad 6.1$ Biclausal description 
1102 Let's suppose that the zigzag construction has its diachronic origin in a biclausal

1103 description of the reciprocal situation, consisting of two medial clauses chained

1104 together, which express the bounded subevents making up the reciprocal situation.

1105 The predicate that expresses the reciprocal action is the same in both clauses but the

1106 argument positions are reversed, according to the template $N P_{j} V$-s $N P_{k}$ and then $N P_{k}$

$1107 V$-s $N P_{j}$, where $\mathrm{j} \neq \mathrm{k}$. Each participant is once encoded as the starting point and once as

1108 the endpoint of a reciprocal subevent. Consider example (57):

1109

1110

(57) $\bar{e} \quad a-t e ̂ m^{\prime}-s-e=a$

3SG.M 3SG.M.O-see.PFV-DS.SEQ-3SG.M.SBJ=MED

1112

1113

$m a k=e \quad a-t e ̂ m^{\prime}-s-e=a$

1115

other=SG.M 3SG.M.O-see.PFV-DS.SEQ-3SG.M.SBJ=MED

1116

'he ${\text { glances at } \operatorname{him}_{\mathrm{k}} \text {, the other }}_{\mathrm{k}}$ glances at $\operatorname{him}_{\mathrm{j}}$, and then ...' (where $\mathrm{j} \neq \mathrm{k}$ )

1117 OR 'he glances at him $_{\mathrm{m}}$, the other $\mathrm{k}$ glances at him $\mathrm{m}$, and then ...' (where

$\mathrm{j} \neq \mathrm{k} \neq \mathrm{m})$

1118

1119 In the reciprocal interpretation of (57) there are two male referents and two

1120 sequential glancing events which are expressed in a clause chaining construction.

1121 Note that reciprocal semantics are not entailed in (57). A non-reciprocal reading is

1122 possible, i.e., a reading where there are three men and two of them (indexed as $\mathrm{j}$ and $1123 \mathrm{k}$ ) glance at the third (indexed as m). 
$1126 \quad 6.2$ The macro-event construction

1128 The next step I suggest is a slight alteration of the biclausal structure in (57) into a

1129 structure that I call the 'macro-event construction'. It is used to describe a temporally

1130 extended macro-event inside which several identical or very similar bounded

1131 subevents, each with their own subject, can be discerned. The main differences to a

1132 biclausal description are that (a) the verbs denoting the subevents are no longer

1133 marked as medial verbs with $=a$ and that $(\mathrm{b})$ a new existential verb $(b l \sim b i)$ enters into

1134 the construction. The existential verb has a subject suffix cross-referencing the whole

1135 set of participants in the complex event, as in (58). In the macro-event construction

1136 material can intervene between the verbs expressing the subevents. The conjunction

$1137 e k a$ 'and' between the two clauses describing the bounded subevents is optional.

1138

1139

1140

(58) $\bar{e} \quad$ a-têm's-e (eka)

3SG.M 3SG.M.O-See.PFV-DS.SEQ-3SG.M.SBJ=MED (and)

1141

1142

mak=e a-têm's-e

1143

other=SG.M 3SG.M.O-see.PFV-DS.SEQ-3SG.M.SBJ=MED

1144

1145

$b l-\emptyset-i o=b e$

1146

exist-IPFV-2/3PL.AN.SBJ=DECL 
1152 As in the biclausal description in (57) above, reciprocal semantics are not entailed 1153 in the 'macro-event construction'. A non-reciprocal reading is possible for (58) with 1154 three men and two of them (indexed as $\mathrm{j}$ and $\mathrm{k}$ ) glancing at the third man (indexed as $1155 \mathrm{~m})$.

1156 The macro-event construction is independently attested in the language in non1157 reciprocal situations. It is employed for temporally extended macro-events consisting 1158 of several bounded subevents, e.g., in (59) where a man tries to rescue his wife from 1159 drowning in a quickly rising tide of water. As in (58) above, the conjunction $e k a$ 1160 'and' between the two clauses describing the bounded subevents is optional.

$$
\text { (59) } i m a k=e
$$$$
\text { mengge-s-e }
$$$$
\text { (eka) }
$$$$
\text { husband=SG.M pull.PFV-DS.SEQ-3SG.M.SBJ (and) }
$$

$$
\text { aai }=e \quad \text { mengge-s-e } \quad b i-n-i b=a
$$
water=SG.N1 pull.PFV-DS.SEQ-3SG.N1.SBJ exist-SEQ-2/3PL.AN.SBJ=MED 'the husband is pulling and the water is pulling (on the woman), they are (doing this) and then ...' [Flood] 
1170 What is described in (59) is of course not a reciprocal action because the agents

1171 are the husband and the water and both are pulling on a single patient, his wife, the

1172 former to rescue her, the latter to drown her. But the example shows that we can set

1173 up the 'macro event' as a separate construction in Mian, independent of reciprocals.

1178 Mian is strongly zero-anaphoric. Overt arguments (NPs or free pronouns) are

1179 typically dropped in discourse, if they are retrievable from the context. A quantitative 1180 analysis of Mian texts shows that in narrative texts the percentage of overtly 1181 expressed nominals can be as low as $25 \%$; even below $15 \%$ in some procedural texts, 1182 where the overt pronoun first singular pronoun $n \bar{e}$ referring to the speaker is 1183 consistently dropped. Therefore, example (58) above was presumably possible 1184 without the overt subject nominals, which yields a structure that looks very much 1185 like the zigzag construction.

1187 (60) a-têm's-s-e 
1194 I assume that not expressing overt subject nominals, resulting in (60), was more or

1195 less restricted to the expression of reciprocal situations. Speakers would have used an

1196 overt NP to facilitate referent identification, if (60) was said to describe a situation in

1197 which two men each glance at a third man. Due to the frequent use of structures like

1198 (60) with dropped nominal arguments for the expression of reciprocal semantics this

1199 construction became specialized as a dedicated reciprocal.

1200 At this stage the subject suffix became conventionalized in the third person 1201 singular masculine (-e), while the object prefixes on the zigzag verbs retained their 1202 ability to indicate gender differences between the reciprocants, as in (61):

1203

1204 (61) a-têm's-e

1205 3SG.M.O-See.PFV-DS.SEQ-3SG.M.SBJ=MED

1206

1207

1208

1209

$$
\text { wa-têm'-s-e }
$$

3SG.F.O-see.PFV-DS.SEQ-3SG.M.SBJ=MED 'They $(\mathrm{F}+\mathrm{M})$ are glancing at each other.'

1210

1211 This is an example for a reciprocal situation between a female and a male

1212 participant. That (61) is a single construction can also be seen from the fact that any

1213 overt subject pronoun has to be in the plural. Any overt subject pronoun must show

1214 the same person and number as the existential verb $b i \sim b l$, which is inflected for 1215 subject, as in (62): 
(62) $\bar{l} \quad$ a-têm's-e

wa-têm's-s-e

3SG.F.O-see.PFV-DS.SEQ-3SG.M.SBJ=MED 'They $(\mathrm{M}+\mathrm{F})$ are glancing at each other.'
1224 This is the endpoint of the development from a biclausal description of a 1225 reciprocal situation to the zigzag-construction in (62). In the remainder of the 1226 historical section I provide some remarks on how the sese-construction fits into this 1227 picture.

1228

1229

$1230 \quad 6.4$ Phonological reduction and reanalysis

1231

1232 The development from the zigzag construction $(V-s-e V$-s-e) to the sese-construction 1233 ( $V$-sese) was possibly due to phonological reduction. The deleted material is struck 1234 through in (63), which otherwise is an exact repetition of (60) above:

1235

1236

(63) $a-t \hat{e} m^{\prime}-s-e$

1237 3SG.M.O-see.PFV-DS.SEQ-3SG.M.SBJ=MED 
1243 Note that the DS suffix $-s$ and the frozen subject suffix $-e$, which belong to the

1244 second erstwhile zigzag verb, are not deleted but now form part of the reciprocal 1245 suffix -sese. The result of this haplology-like reduction is illustrated in (64), where 1246 the segment sequence /s $\varepsilon$ s / has been reanalyzed as the reciprocal suffix -sese. Note 1247 that (64) is hypothetical and synchronically unattested. The sese-construction 1248 undergoes univerbation (see 6.5 below).

(64) Hypothetical construction:

$$
\text { a-têm'-sese }
$$

3SG.M.O-see.PFV-RECP exist-IPFV-2/3PL.AN.SBJ=DECL 'They (M+M) are glancing at each other.' $b l-\emptyset-i o=b e$

exist-IPFV-2/3PL.AN.SBJ=DECL 'They are glancing at each other.' 
1262 explanation of the facts. An obvious first step towards a clearer picture would be to

1263 compare reciprocal constructions in neighboring languages.

1264

1265

$1266 \quad 6.5$ Univerbation

1267

1268 The final step in the development of the sese-construction is univerbation of the verb

1269 bearing the suffix -sese with the existential verb, yielding (65):

1270

1271

(65) $a$-têm'sese-bl- Ø-io=be

1272 3SG.M.O-see.PFV-RECP-exist-IPFV-2/3PL.AN.SBJ=DECL 'They (M+M) are glancing at each other.'

1274

1275 In contemporary Mian the whole verb complex in (65) forms a single

1276 phonological word with respect to tone assignment and the initial $/ \mathrm{b} / \mathrm{in}$ the 1277 existential verb is not prenasalized, which is would be in isolation.

1278

1279

$1280 \quad 7 \quad$ Conclusion

1281

1282 Mian has two related monosemous constructions for the description of reciprocal 1283 situations, the zigzag construction and the possibility of inflecting a verb with the 1284 reciprocal suffix -sese, where the form of this suffix is the result of a fusion of the 
1285 zigzag type. Both of these are complex and typologically unusual in that they employ 1286 a verb-marking strategy yet require both reciprocant argument positions to be filled 1287 and verbs to remain transitive. In each case the existential verb indexes all 1288 reciprocants with a plural subject suffix and marks the whole complex event as a 1289 joint activity.

1290 While the zigzag type of reciprocal construction has also been reported in other 1291 TNG languages, such as Amele and Hua, the fused type is so far only attested in 1292 Mian. The sese-construction is restricted to perfective aspect, while the zigzag 1293 construction has a perfective variant with the DS suffix $-s$ 'DS, sequential' and an 1294 imperfective variant with the DS suffix $-b$ 'DS, simultaneous'. In each case, the S/R 1295 meaning marked on the first zigzag verb is interpreted with respect to the second 1296 zigzag verb and vice versa.

1297 The important features of the zigzag construction are that there are three 1298 subevents integrated into a single clause. The first two are expressed by the zigzag 1299 verbs, each of which is inflected for DS, and the third is expressed by an existential 1300 verb, which is always inflected for a plural subject. The subject is indicated on both 1301 zigzag verbs by a conventionalized subject suffix of the form - $e$, which is the third 1302 person singular masculine.

1303 The zigzag verbs express the respective reciprocal subevents within the larger 1304 event described by the whole clause. The second zigzag verb describes the same 1305 event but with converse argument configurations. The zigzag construction has to be 1306 used for sequential reciprocity between two participants who differ in biological sex. 
1307 The zigzag construction can be derived diachronically from a biclausal description 1308 involving a clause chain in which both verbs are marked for different subject 1309 following. I showed that this is a plausible development because the S/R marking 1310 from the biclausal description is still in operation in the zigzag construction, albeit in 1311 a circular fashion. The zigzag type has been fused into the sese-construction, in 1312 which the second sequence /sc/ is a remnant of the second zigzag verb, namely the 1313 DS suffix followed by the conventionalized subject suffix.

1314 Reciprocal constructions are interesting cross-linguistically because they have 1315 complex events and show a wide range of different encoding strategies in the 1316 languages of the world. This study provides an in-depth analysis of the complex 1317 morphology and semantics of a typologically very interesting type of reciprocal 1318 construction, which has not yet been analyzed in detail in the existing literature on 1319 reciprocals. The study pushes back the limits of our knowledge of Papuan languages 1320 and contributes to the typology of reciprocal constructions.

\section{Abbreviations}

13241 - first person, 2 - second person, 3 - third person, AN - animate, $\mathrm{CP}$ - classificatory 1325 prefix, DECL - declarative, DS - different subject, DU - dual, F - feminine, GPST 1326 general past, HORT - hortative, HPST - hesternal past, IMP - imperative, INCL 1327 inclusive, INF - infinitive, IO - indirect object, IPFV - imperfective, M -masculine, 1328 MED - medial verb, N1 - neuter 1, N2 - neuter 2, O - object, PFV - perfective, PL 1329 plural, PRED - predicate marker, $\mathrm{R}$ - recipient, REAL - realis, RECP - reciprocal, SBJ - 
1330 subject, SEQ - sequential, SG - singular, SIM - simultaneous, SS - same subject, 1331 TODPAST - today past.

\section{References}

1335 Aikhenvald, Alexandra Y. 2000. Classifiers. Oxford: Oxford University Press.

1336 Behrens, Leila. 2007. Backgrounding and suppression of reciprocal participants: A 1337 cross-linguistic study. Studies in Language 31(2). 327-408.

1338 Brown, Robert. 1981. Semantic aspects of Waris predication. In Franklin, Karl (ed.), 1339 Syntax and semantics in Papua New Guinea languages. Ukarumpa: Summer $1340 \quad$ Institute of Linguistics, 93-124.

1341 Comrie, Bernard. 2003. Recipient person suppletion in the verb "give”. In Mary Ruth 1342 Wise, Thomas N. Headland \& Ruth M. Brend (eds.), Language and life: Essays in 1343 memory of Kenneth L. Pike, 265-281. Dallas: SIL International and the University 1344 of Texas at Arlington.

1345 Dalrymple, Mary, Makoto Kanazawa, Sam A. Mchombo \& Stanley Peters. 1994. 1346 What do reciprocals mean?, Proceedings of the Fourth Conference on Semantics 1347 and Linguistic Theory, University of Rochester, New York, May 1994.

1348 Dalrymple, Mary, Makoto Kanazawa, Sam A. Mchombo \& Stanley Peters. 1998. 1349 Reciprocal expressions and the concept of reciprocity. Linguistics and Philosophy 1350 21(1). 159-210. 
1351 Dimitriadis, Alexis. 2008. Irreducible symmetry in reciporcal constructions. In

1352 Ekkehard König \& Volker Gast (eds.), Reciprocals and reflexives: Cross1353 linguistic and theoretical explorations, 375-409. Berlin: Mouton de Gruyter.

1354 Donohue, Mark. 1997. Tone systems in New Guinea. Linguistic Typology 1(3). 3471355386.

1356 Evans, Nicholas. 2008. Reciprocal constructions: Towards a structural typology. In 1357 Ekkehard König \& Volker Gast (eds.), Reciprocals and reflexives: Cross1358 linguistic and theoretical explorations, 33-104. Berlin: Mouton de Gruyter.

1359 Evans, Nicholas. 2010. Complex events, propositional overlay and the special status 1360 of reciprocal clauses. In Sally Rice \& John Newman (eds.), Empirical and 1361 experimental methods in cognitive/functional research, 1-40. Stanford: CSLI.

1362 Evans, Nicholas, Stephen C. Levinson, Nicholas J. Enfield, Alice Gaby \& Asifa 1363 Majid. 2004. Reciprocals. In Asifa Majid (ed.), Field manual: Volume 9, 25-30. 1364 Nijmegen: Max Planck Institute for Psycholinguistics.

1365 Evans, Nicholas, Alice Gaby, Stephen C. Levinson \& Asifa Majid. 2011. 1366 Reciprocals and semantic typology. Amsterdam: John Benjamins.

1367 Fedden, Sebastian. 2010. Ditransitives in Mian. In Andrej Malchukov, Martin 1368 Haspelmath \& Bernard Comrie (eds.), Studies in ditransitive constructions: A 1369 comparative handbook, 456-485. Berlin: De Gruyter Mouton.

1370 Fedden, Sebastian. 2011. A grammar of Mian (Mouton Grammar Library 55). Berlin: 1371 De Gruyter Mouton. 
1372 Fedden, Sebastian. 2012. Origin of switch-reference markers in Mian. In Volker Gast

1373 \& Holger Diessel (eds.), Clause combining in cross-linguistic perspective.

1374 Berlin: De Gruyter Mouton.

1375 Foley, William A. 2000. The languages of New Guinea. Annual Review of 1376 Anthropology 29. 357-404.

1377 Foley, William A. \& Robert Van Valin. 1984. Functional syntax and universal 1378 grammar. Cambridge: Cambridge University Press.

1379 Frajzyngier, Zygmunt \& Traci S. Curl (eds.). 2000. Reciprocals: Form and function 1380 (Typological Studies in Language 41). Amsterdam: John Benjamins.

1381 Haiman, John. 1980. Hua: A Papuan language of the Eastern Highlands of New $1382 \quad$ Guinea. Amsterdam: John Benjamins.

1383 Healey, Alan. 1964. A survey of the Ok family of languages, reconstructing proto1384 Ok. Canberra: Australian National University PhD dissertation.

1385 Hopper, Paul \& Sandra Thompson. 1980. Transitivity in grammar and discourse. $1386 \quad$ Language 56(2). 251-299.

1387 Keenan, Edward. 1984. Semantic correlates of the ergative/absolutive distinction. $1388 \quad$ Linguistics 22(2). 197-223.

1389 König, Ekkehard \& Volker Gast (eds.). 2008. Reciprocals and reflexives: Cross$1390 \quad$ linguistic and theoretical explorations. Berlin: Mouton de Gruyter.

1391 König, Ekkehard \& Shigehiro Kokutani. 2006. Towards a typology of reciprocal 1392 constructions: Focus on German and Japanese. Linguistics 44(2). 271-302.

1393 Levinson, Stephen C. 2011. Reciprocals in Yélî Dnye, the Papuan language of 1394 Rossel Island. In Nicholas Evans, Alice Gaby, Stephen C. Levinson \& Asifa 
1395 Majid (eds.), Reciprocals and semantic typology, 177-194. Amsterdam: John 1396 Benjamins.

1397 Lichtenberk, František. 1985. Multiple uses of reciprocal constructions. Australian $1398 \quad$ Journal of Linguistics 5(1). 19-41.

1399 Marlett, Stephen A. 2005. A typological overview of the Seri language. Linguistic $1400 \quad$ Discovery 3(1). 54-73.

1401 Moyse-Faurie, Claire. 2008. Constructions expressing middle, reflexive and 1402 reciprocal situations in some Oceanic languages. In Ekkehard König \& Volker 1403 Gast (eds.), Reciprocals and reflexives: Cross-linguistic and theoretical 1404 explorations, 105-168. Berlin: Mouton de Gruyter

1405 Nedjalkov, Vladimir P. (ed.). 2007a. Reciprocal constructions (Typological Studies 1406 in Language 71). 5 vols. Amsterdam: John Benjamins.

1407 Nedjalkov, Vladimir P. 2007b. Overview of the research: Definitions of terms, 1408 framework, and related issues. In Vladimir P. Nedjalkov (ed.), Reciprocal 1409 constructions. Vol 1, 3-114. Amsterdam: John Benjamins.

1410 Nichols, Johanna. 1996. Head-marking and dependent marking grammar. Language $1411 \quad 62(1) .56-119$.

1412 Pawley, Andrew. 2005. The chequered career of the Trans New Guinea hypothesis: 1413 Recent research and its implications. In Andrew Pawley, Robert Attenborough, 1414 Jack Golson \& Robin Hide (eds.), Papuan pasts: Cultural, linguistic and 1415 biological histories of Papuan-speaking peoples, 67-108. Canberra: Pacific 1416 Linguistics. 
1417 Roberts, John R. 1987. Amele (Croom Helm Descriptive Grammar Series). London: 1418 Croom Helm.

1419 Roberts, John R. 1998. Give in Amele. In John Newman (ed.), The linguistics of 1420 giving, 1-33. Amsterdam: John Benjamins.

1421 Robinson, Stuart. 2011. Reciprocals in Rotokas. In Nicholas Evans, Alice Gaby, 1422 Stephen C. Levinson \& Asifa Majid (eds.), Reciprocals and semantic typology, 1423 195-211. Amsterdam: John Benjamins.

1424 Reesink, Ger P. 1983. Switch reference and topicality hierarchies. Studies in $1425 \quad$ Language 7(2). 215-246.

1426 Ross, Malcolm. 2005. Pronouns as a preliminary diagnostic for grouping Papuan 1427 languages. In Andrew Pawley, Robert Attenborough, Jack Golson \& Robin Hide 1428 (eds.), Papuan pasts: Cultural, linguistic and biological histories of Papuan1429 speaking peoples, 15-66. Canberra: Pacific Linguistics.

1430 Seiler, Walter. 1983. From verb serialization to noun classification. Unpublished ms. 1431 Australian National University.

1432 Smith, Jean \& Pamela Weston 1986. Gode dowan wengobe: Mian weng New 1433 Testament (God's Good News. The New Testament in the Mian language). South 1434 Holland, IL: World Home Bible League.

1435 Stirling, Leslie. 1993. Switch-reference and discourse representation. Cambridge: 1436 Cambridge University Press.

1437 Voorhoeve, Bert. 2005. Asmat-Kamoro, Awyu-Dumut and Ok: An enquiry into their 1438 linguistic relationships. In Andrew Pawley, Robert Attenborough, Jack Golson \& 
1439 Robin Hide (eds.), Papuan pasts: Cultural, linguistic and biological histories of 1440 Papuan-speaking peoples, 145-166. Canberra: Pacific Linguistics.

1441 Wegener, Claudia. 2011. Expression of reciprocity in Savosavo. In Nicholas Evans, 1442 Alice Gaby, Stephen C. Levinson \& Asifa Majid (eds.), Reciprocals and semantic 1443 typology, 213-224. Amsterdam: John Benjamins.

1444 Wurm, Stephen. 1982. Papuan languages of Oceania. Tübingen: Narr.

1445 Z'graggen, John A. 1975. The languages of the Madang district, Papua New Guinea. 1446 Pacific Linguistics B-41. Canberra: Pacific Linguistics.

1447 Z'graggen, John A. 1980. A comparative wordlist of the Mabuso languages, Madang 1448 Province, Papua New Guinea. Pacific Linguistics D-32. Canberra: Pacific 1449 Linguistics. 
Figures - Reciprocals in Mian

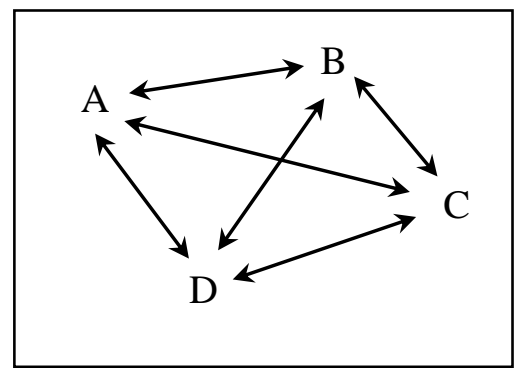

Figure 1. Strong reciprocity

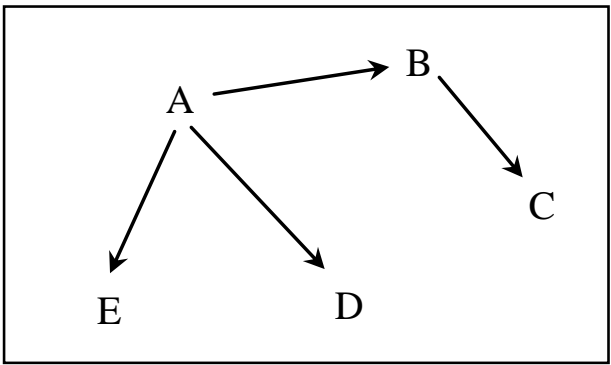

Figure 2. Melee configuration

$$
\mathrm{A} \longrightarrow \mathrm{B} \longrightarrow \mathrm{C} \longrightarrow \mathrm{D} \longrightarrow \mathrm{E}
$$

Figure 3. Chaining situation

$$
\mathrm{A} \longleftrightarrow \mathrm{B} \longleftrightarrow \mathrm{C} \longleftrightarrow \mathrm{D} \longleftrightarrow \mathrm{E}
$$

Figure 4. Adjacency 
2

3

4

5

6

7

8

10

11

12 Table 3. Reciprocal subtypes in Mian

\begin{tabular}{|c|c|c|c|c|c|c|c|c|c|}
\hline \multirow[t]{2}{*}{$\begin{array}{l}\text { Subtype } \\
\text { ID }\end{array}$} & \multirow[t]{2}{*}{ Reciprocal } & \multirow[t]{2}{*}{$\begin{array}{l}\text { Object } \\
\text { affix is }\end{array}$} & \multirow[t]{2}{*}{ SEQ } & \multirow[t]{2}{*}{ SIM } & \multicolumn{2}{|c|}{$\begin{array}{l}\text { Recipro- } \\
\text { cants }\end{array}$} & \multicolumn{2}{|l|}{ Gender } & \multirow{2}{*}{$\begin{array}{l}\text { Illustrated } \\
\text { in } \\
\text { examples }\end{array}$} \\
\hline & & & & & 2 & $3+$ & Mixed & Same & \\
\hline A & -sese & SG.M & $\checkmark$ & $x$ & $\checkmark$ & $x$ & $x$ & $\checkmark$ & (2) \\
\hline $\mathrm{B}$ & -sese & SG.F & $\checkmark$ & $x$ & $\checkmark$ & $x$ & $x$ & $\checkmark$ & (3) \\
\hline $\mathrm{C}$ & -sese & PL & $\checkmark$ & $\checkmark$ & $x$ & $\checkmark$ & $\checkmark$ & $\checkmark$ & (1) \\
\hline $\mathrm{D}$ & -sese & absent & $\checkmark$ & $\checkmark$ & $\checkmark$ & $\checkmark$ & $\checkmark$ & $\checkmark$ & $(30)$ \\
\hline $\mathrm{E}$ & $-s e \ldots-s e$ & M.SG & $\checkmark$ & $x$ & $\checkmark$ & $x$ & $x$ & $\checkmark$ & (5) \\
\hline $\mathrm{F}$ & -se ... -se & F.SG & $\checkmark$ & $x$ & $\checkmark$ & $x$ & $x$ & $\checkmark$ & (6) \\
\hline G & $-s e \ldots-s e$ & $\begin{array}{l}\text { SG.F + } \\
\text { SG.M } \\
\end{array}$ & $\checkmark$ & $x$ & $\checkmark$ & $x$ & $\checkmark$ & $x$ & (7) \\
\hline $\mathrm{H}$ & -se ... -se & PL & $\checkmark$ & $\checkmark$ & $x$ & $\checkmark$ & $\checkmark$ & $\checkmark$ & (4) \\
\hline I & $-s e \ldots-s e$ & absent & $\checkmark$ & $\checkmark$ & $\checkmark$ & $\checkmark$ & $\checkmark$ & $\checkmark$ & (35) \\
\hline
\end{tabular}

\begin{tabular}{|c|c|c|c|c|c|c|c|c|}
\hline \multirow[t]{2}{*}{ Gender } & \multicolumn{2}{|c|}{ Subject } & \multicolumn{2}{|c|}{ Object } & \multicolumn{2}{|c|}{$\begin{array}{c}\text { Recipient } \\
(\mathrm{PFV})\end{array}$} & \multicolumn{2}{|c|}{$\begin{array}{c}\text { Recipient } \\
\text { (IPFV) }\end{array}$} \\
\hline & $\mathrm{Sg}$ & $\mathrm{Pl}$ & $\mathrm{Sg}$ & $\mathrm{Pl}$ & $\mathrm{Sg}$ & $\mathrm{Pl}$ & $\mathrm{Sg}$ & $\mathrm{Pl}$ \\
\hline Masculine & $-e$ & \multirow{2}{*}{$-i b \sim-i o$} & $a-$ & \multirow{2}{*}{$y(a)-\sim i-$} & $-a$ & \multirow{2}{*}{$-e$} & $-h a$ & \multirow{2}{*}{$-y e$} \\
\hline Feminine & $-O$ & & $w a-$ & & $-O$ & & $-w e$ & \\
\hline
\end{tabular}

Table 1. Classificatory prefixes (in the third person)

\begin{tabular}{|l|l|c|c|}
\hline \multirow{3}{*}{ Person } & \multirow{2}{*}{ Classes } & \multicolumn{2}{|c|}{ Classificatory prefixes } \\
\cline { 3 - 4 } & & Singular & Plural \\
\hline \multirow{4}{*}{3} & M-class & dob- $\sim$ do- & \multirow{2}{*}{ dol- $\sim d l-\sim d o-$} \\
\cline { 2 - 4 } & F-class & om- & \\
\cline { 2 - 4 } & Long object & tob- $\sim$ to- & tebel $-\sim$ tebe- \\
\cline { 2 - 4 } & Bundle-like object & gol $-\sim$ go- & gulel $-\sim$ gule- \\
\cline { 2 - 4 } & Covering object & gam- & gemel $-\sim$ geme- \\
\cline { 2 - 4 } & Residue class & ob- $\sim o_{-}$ & ol- $\sim o_{-}$ \\
\hline
\end{tabular}
9

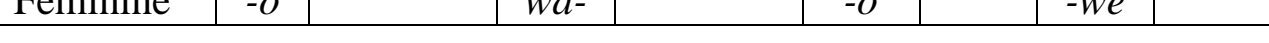

13

\section{Tables - Reciprocals in Mian}

14 